\title{
A importância das ações de proteção e Defesa Civil na minimização de desastres em edificações e áreas de risco
}

The importance of Civil Defense and protection actions in minimizing disasters in edifications and risk areas

La importancia de las acciones de Defensa y protección Civil en la minimización de desastres en edificaciones y áreas de riesgo

\section{Resumo}

A falta de recursos, supervalorização dos terrenos, falta de mão de obra especializada e adensamento descontrolado de edificações das cidades fazem com que a população execute construções de edificações em áreas de riscos, sem acompanhamento de profissionais devidamente habilitados, que não utilizam boas técnicas construtivas e materiais de construção adequados, causando assim risco de desastres. Cabe aos municípios, com o apoio dos Estados quando for necessário, atuar na minimização de desastres nas edificações e áreas de risco, através de efetivas ações de proteção e defesa civil. Daí a importância de que os técnicos de defesa civil tenham conhecimentos específicos das legislações vigentes e das manifestações patológicas apresentadas pelas edificações, para assim atuarem de forma adequada às situações de risco. No presente trabalho são apresentados 2 (dois) estudos de casos de situações de riscos vivenciados pelo autor, além de proposta de documentação específica para atuação das defesas civis em resposta às situações de desastres.

Palavras-chave: Minimização de desastres; Manifestações patológicas; Defesa civil.

\begin{abstract}
The lack of resources, the overvaluation of land, the lack of specialized labor and the uncontrolled densification of buildings in cities make the population carry out constructions in risk areas, without monitoring by properly qualified professionals, who do not use good construction techniques and adequate constructive materials causing disaster risk. It is up to the municipalities, with the support of the States, when necessary, to act in the minimization of disasters in buildings and risk areas, through effective actions of protection and civil defense. Hence the importance of civil defense technicians having specific knowledge of the legislation in force and the pathological manifestations presented by the edifications, in order to act properly in risky situations. In the present work, 2 (two) case studies of risk situations experienced by the author are presented, as well as a proposal for specific documentation for the civil defense action in response to disaster situations.
\end{abstract}

Keywords: Disaster minimization; Pathological manifestations; Civil defense.

\section{Resumen}

La escasez de recursos, la sobrevaloración del suelo, la falta de mano de obra especializada y la densificación incontrolada de edificaciones en las ciudades hacen que la población lleve a cabo construcciones de edificaciones en zonas de riesgo, sin seguimiento por profesionales debidamente cualificados, que no emplean buenas técnicas constructivas y edificación adecuada. materiales, causando riesgo de desastres. Corresponde a los municipios, con el apoyo de los Estados cuando sea necesario, actuar en la minimización de desastres en edificaciones y áreas de riesgo, a través de acciones efectivas de protección y defensa civil. De ahí la importancia de que los técnicos de Defensa Civil tengan un conocimiento específico de la legislación vigente y de las manifestaciones patológicas que presentan las edificaciones, para actuar de forma adecuada en situaciones de riesgo. En el presente trabajo se presentan 2 (dos) estudios de caso de situaciones de riesgo vividas por el autor, además de una propuesta de documentación específica para la actuación de defensas civiles ante situaciones de desastre.

Palabras clave: Minimización de desastres; Manifestaciones patológicas; Defensa civil. 


\section{Introdução}

Assim como um acidente aeronáutico, diversos são os fatores que podem levar uma edificação ao colapso. As normas técnicas relacionadas às construções sempre utilizam coeficientes com elevada margem de segurança para dimensionamento das estruturas e do emprego de materiais. Portanto, uma falha em determinada parte da edificação, pode ser compensada com um superdimensionamento em outra parte, porém, um excesso de falhas pode causar danos irreversíveis às edificações (Freitas \& Nunes, 2012).

Segundo Torga (2020), a construção civil está ligada diretamente ao desenvolvimento econômico do País. Um dos principais problemas que atingem esse setor é a falta de contratação de profissional habilitado para projetar e executar as obras. No Brasil, é corrente o hábito da população em promover obras corretivas em vez de prevenir com planejamento e manutenções periódicas, havendo uma preocupação apenas com o custo imediato da obra, deixando a segurança de lado. Nesse sentindo, costumam-se executar construções ilegais, sem o devido alvará e as licenças ambientais; executam "puxadinhos", ampliando ainda mais a edificação irregular e, muitas vezes, utilizando esses ambientes de forma inadequada para a ocupação para a qual foi construída. Todos os problemas citados geram as chamadas manifestações patológicas, sendo algumas delas: fissuras, rachaduras, corrosão, eflorescências, bolores, recalque diferencial, etc.

As edificações podem ser comparadas aos seres humanos, pois as pessoas precisam dos devidos cuidados durante toda sua vida para não adoecerem, e caso fiquem doentes devem passar por correto tratamento de saúde, acompanhadas por profissional médico, para que a situação não se agrave e elas venham a falecer. Já as edificações precisam de manutenções periódicas durante sua vida útil, para que não venham apresentar manifestações patológicas; e, caso isso aconteça, nelas devem ser executados reparos com acompanhamento por profissional devidamente habilitado (técnico, engenheiro ou arquiteto) em seu conselho, caso contrário, as edificações podem sofrer colapso estrutural.

$\mathrm{O}$ aumento crescente da necessidade de habitações em áreas super povoadas provocou o surgimento de novas construções em locais indevidos, levando a acidentes muitas vezes fatais, provocados por deslizamentos, inundações e incêndios. As áreas de risco são locais impróprios para a construção de edificações, pois essas áreas são irregulares e, muitas vezes, apresentam solos pouco estáveis e sem coesão, o que leva ao desmoronamento e deslizamento de terras. Para se construir nesse tipo de terreno, são necessários projetos complexos, mão de obra qualificada e materiais de construção com elevado preço; e a necessidade desses procedimentos fazem com que os moradores adotem práticas construtivas e utilização de materiais errados (Medeiros, 2008; Silva et al., 2021).

Quando as construções são executadas de forma irregular, em áreas de riscos, sem manutenções e reparos adequados, cabe a interferência do poder público para tomar as providências que julgar necessárias, a fim de se evitarem tragédias. Sendo assim, foi estabelecida pela Presidência da República a Lei $\mathrm{n}^{\circ}$ 12.608, de 10 de abril de 2012, que institui a Política Nacional de Proteção e Defesa Civil (PNPDEC) e dá outras providências, estabelecendo a competência da União, Estados e Municípios em adotar medidas necessárias à redução do risco de desastres (Brasil, 2012).

Nesse sentido, o presente artigo tem como objetivo responder os seguintes questionamentos: Qual é o órgão público responsável por tomar medidas de proteção imediatas em caso de situação de riscos a edificações e áreas? Em quais situações o técnico de defesa civil deve aplicar autos de notificação, interdição e embargo? Quando e por quem deve ser elaborado o parecer técnico? Quais as principais dificuldades enfrentadas pelo técnico de defesa civil nas tomadas de decisão? O que pode acontecer, caso o técnico de defesa civil não tome as corretas providências em caso de risco iminente de desastre? Qual o papel da Coordenadoria Estadual de Proteção e Defesa Civil na minimização de desastres em edificações e áreas de risco? 


\section{Metodologia}

O presente trabalho utilizou metodologia de pesquisa qualitativa, através de estudo teórico bibliográfico em livros, artigos, manuais e trabalhos de conclusão de cursos sobre patologias das construções. Também houve estudos da Lei no 12.608 , de 10 de abril de 2012; da Lei n ${ }^{\circ}$ 12.608, de 10 de abril de 2012, que institui a Política Nacional de Proteção e Defesa Civil (PNPDEC) e dá outras providências. Os resultados apresentados pela presente pesquisa constam de 2 (dois) estudos de casos vivenciados pelo autor, permitindo a compreensão e interpretação dos fatos observados através de descrições e relatórios fotográficos. Em um estudo é apresentada uma situação de risco imediato a uma área, onde se encontrava uma igreja e uma residência unifamiliar. E, no outro estudo, foi apresentada uma ponte com diversos problemas estruturais, na qual foi necessária a intervenção dos técnicos em defesa civil para evitar um possível desastre. Em ambos os casos, utiliza-se de estudos comparativos apresentados em bibliografias e exigências de legislação específica.

Também como resultado da pesquisa, foi apresentado modelo de documentos específicos que podem ser utilizados pelos técnicos de defesa civil em suas atuações em caso de riscos de desastres. Esses modelos apresentados foram elaborados através de estudo comparativo com outros modelos desses documentos utilizados pelo Corpo de Bombeiros Militar do Estado do Tocantins e pela Defesa Civil do município de Maricá-RJ, no qual foram selecionadas pelo autor as informações ideais e completas que devem haver nesses documentos que são: auto de notificação e auto de interdição.

\section{Desenvolvimento}

\subsection{Competências legais de Ações de Proteção e Defesa Civil (Estados e Municípios)}

De acordo com Brasil (2012), compete aos Estados: identificar e mapear as áreas de risco e realizar estudos de identificação de ameaças, suscetibilidades e vulnerabilidades, em articulação com a União e os Municípios; realizar o monitoramento meteorológico, hidrológico e geológico das áreas de risco, em articulação com a União e os Municípios; apoiar, sempre que necessário, os Municípios no levantamento das áreas de risco, na elaboração dos Planos de Contingência de Proteção e Defesa Civil e na divulgação de protocolos de prevenção e alerta e de ações emergenciais; dentre outros.

Compete aos Municípios: identificar e mapear as áreas de risco de desastres; promover a fiscalização das áreas de risco de desastre e vedar novas ocupações nessas áreas; vistoriar edificações e áreas de risco e promover, quando for o caso, a intervenção preventiva e a evacuação da população das áreas de alto risco ou das edificações vulneráveis; manter a população informada sobre áreas de risco e ocorrência de eventos extremos, bem como sobre protocolos de prevenção e alerta e sobre as ações emergenciais; dentre outros (Brasil, 2012).

\subsection{Manifestações Patológicas em Edificações}

Para que sejam executadas efetivas ações de proteção e defesa civil, o técnico de Proteção e Defesa Civil deve deter conhecimento técnico das principais manifestações patológicas encontradas nas edificações e áreas de risco; e, caso não tenha tal conhecimento, ele deve solicitar apoio a profissional devidamente habilitado, compreendendo assim os riscos que essas anomalias podem gerar, caso não sejam tomadas medidas de segurança necessárias, a fim de se evitarem desastres.

Entende-se por Patologia como um campo da Engenharia que estuda a origem, os sintomas e os defeitos nas construções. Essas anomalias nas edificações são denominadas manifestações patológicas, e essas patologias não ocorrem de forma isolada e sem motivo; normalmente, há alguma relação com erros cometidos em algumas das fases do processo de concepção de um edifício, da eficiência da estrutura, dos métodos construtivos, da agressividade do meio e da falta de manutenções. Daí a necessidade de se conhecer a origem do problema e o histórico da construção (Helene \& Figueiredo, 2003; Aleixo; Eloy; Silva, 2019). Os principais causadores de manifestações patológicas são provenientes de erros na fase de projeto 
e na execução da obra, e isso se deve provavelmente pela má formação do profissional técnico responsável e pela mão de obra desqualificada (Barros, 2019).

Essas doenças, pontuais ou generalizadas, causam deterioração do material, modificando suas propriedades físicas e estruturais. Qualquer edificação pode sofrer ataques por agentes agressivos, podendo acarretar o aparecimento de trincas, fissuras, recalques diferenciais, eflorescências, corrosão das armaduras e outras situações adversas (Iantas, 2010; Carneiro et al., 2019). Segundo Vitório (2003) e Gomes et al. (2017), fendas, rachaduras, trincas e fissuras são manifestações patológicas nas quais ocorrem aberturas superficiais em um material sólido, causadas pela movimentação, sobrecarga em pilares, vigas e lajes (erros de dimensionamento das peças), e retração térmica do material empregado na construção. Elas se diferenciam conforme a espessura de suas aberturas, havendo limites máximos aceitos pré-estabelecidos pela NBR 6118/2003. A ocorrência de fissuras por sua vez, em um determinado componente estrutural, provoca a redistribuição de tensões nos elementos fissurados e implicam na necessidade de diagnóstico e reparo adequado; caso contrário, pode ocorrer a ruptura ou instabilidade da estrutura. Essas aberturas facilitam a penetração de agentes agressivos do meio para as camadas internas da estrutura, o que acelera ainda mais o processo de deterioração (Vitório, 2003).

Outro fator deteriorante é a corrosão das armaduras, que é o resultado do processo eletroquímico das reações de oxirredução, no qual o oxigênio e a umidade presente no ar atmosférico reagem com os íons de ferro presentes no aço, provocando a formação de ferrugem. Essa decomposição do aço promove a perda de seção das peças metálicas, diminuindo a resistência à tração para a qual a peça de concreto armado foi dimensionada. A presença de gás carbônico e dióxido de enxofre e outras substâncias ácidas presentes no ar aceleram o processo de corrosão. No concreto armado, a corrosão pode se manifestar de forma generalizada, pela superfície da armadura, ou de forma pontual e profunda. Caso as peças que apresentam corrosão não sejam reparadas, poderá vir a causar risco de ruptura a estrutura (Medeiros, 2008).

Eflorescências são formações de sais cristalizados que ocorrem devido à percolação da água, rica em sais, no interior da alvenaria ou do concreto. Essa lixiviação dos compostos cimentícios promove a formação de compostos pulverulentos, compreendendo em manchas que afloram a superfície, normalmente com aparência esbranquiçada. A princípio, as eflorescências não causam danos à estrutura da edificação; porém, com o passar do tempo, a lixiviação promove a remoção de silicato de cálcio hidratado, que é um dos principais componentes responsáveis pela resistência mecânica do cimento, podendo assim causar danos à segurança da edificação (Souza, 1997).

Por outro lado, o recalque diferencial, é uma das manifestações patológicas mais significativas, pois trata-se de um fenômeno que ocorre quando uma edificação sofre um rebaixamento devido ao adensamento do solo sob sua fundação; ou seja, parte do edifício rebaixa mais que outra parte, gerando esforços estruturais não previstos, causando aparecimentos de trincas e rachaduras na edificação. Esse fato ocorre devido à falta de estudo de sondagem do solo antes do dimensionamento da fundação, ou por erros de dimensionamento (Milititsky et al., 2015).

Dentre outras manifestações patológicas, pode-se citar a instabilidade de taludes de terra, problema causado por fatores naturais (chuvas, intempéries, atividades sísmicas) ou por fatores humanos com cortes inadequados em aterro, visando construir edificações. Esse último atrelado à retirada de vegetação e drenagem deficiente levam à ocorrência de deslizamentos, devendo ser tomadas as devidas providências, para a estabilização imediata do talude, a fim de evitar eventual catástrofe (Silva, 2012). Outra manifestação patológica muito comum nas edificações, é o aparecimento de bolores (fungos), manchas esverdeadas que normalmente surgem na parte inferior das paredes, em áreas úmidas ou devido à percolação da umidade proveniente do solo. Devido à falta de impermeabilização eficiente da viga baldrame, microrganismos se desenvolvem na estrutura, causando aparência insalubre ao ambiente, prejudicando sua estética, degradação dos materiais, interferindo na qualidade ambiental das edificações e provocando problemas respiratórios as pessoas (Guerra \& Peres, 2011). 
E por fim, as infiltrações provocadas pela formação do acúmulo de água sobre a superfície da edificação, na qual ocorre a penetração da água pelas camadas superficiais, devido à ação da gravidade e à existência de vazios. As infiltrações também podem ocorrer pela falta de impermeabilização de elementos construtivos, e caso isso não seja sanado, podem-se causar eflorescências, acelerar o processo de corrosão das armaduras e danificar aparelhos eletrônicos, mobílias e instalações elétricas, podendo causar curto-circuito e até mesmo incêndios (Souza et al., 2011; Ribeiro et al., 2019).

\subsection{Documentação Específica para Ações de Proteção e Defesa civil}

Para que as ações de proteção e defesa civil sejam oficialmente efetivadas, devem ser lavrados documentos específicos referentes à decisão tomada pelo técnico de Proteção e Defesa Civil, buscando resguardar e estabelecer exigências em prol da segurança contra incidentes e desastres. Dentre os principais documentos específicos, pode-se citar: notificação, auto de interdição, auto de desinterdição, embargo, desembargo, parecer técnico e laudo técnico.

De acordo com Brasil (2007), entende-se por Auto de Notificação o documento específico em que ao responsável pelo estabelecimento ou área de risco é solicitado corrigir as irregularidades apontadas pelo agente, no momento da ocorrência, em prazo pré-estabelecido. Os autos devem ser emitidos nos casos que não apresentarem riscos iminentes à vida ou ao patrimônio. Já o Auto de Embargo é aplicado para a paralisação de obras ou serviços que apresentarem risco iminente, ficando o responsável ou proprietário da obra impedido de dar continuidade aos serviços, até que sejam sanadas as pendências registradas nesse documento.

O Auto de Interdição é lavrado quando houver risco iminente por comprometimento estrutural ou qualquer tipo de risco que prejudique a segurança das pessoas e patrimônio existentes na edificação ou área de risco. Ocorrendo interdição ou embargo, a Prefeitura Municipal e as Polícias Judiciária e Militar devem ser comunicadas, visando garantir o exercício do poder de polícia e dos demais procedimentos administrativos e criminais. Havendo descumprimento do embargo ou da interdição, o fato é comunicado à Polícia Judiciária, a fim de instruir processo criminal cabível. Cessado o motivo que deu causa à interdição ou ao embargo, é lavrado termo de desinterdição ou desembargo, em prazo determinado pelas diretrizes legais municipais (Brasil, 2007).

Segundo Grigol (2020), o Parecer Técnico, muitas vezes solicitado por autoridade competente, é um documento técnico específico de caráter opinativo, elaborado por profissional especializado, devidamente habilitado e registrado em conselho profissional específico, que realiza análises através de inspeções in loco, utilizando de seu conhecimento técnico para constatar as condições físicas e de segurança de uma edificação, área de risco ou de um serviço, reconhecendo suas características relevantes.

Já o Laudo Técnico é um documento de assistência jurídica, em que consta análise técnica realizada por profissional especializado, devidamente habilitado e registrado em conselho profissional específico, devendo ser fundamentado em normas técnicas e métodos científicos, sem constatações subjetivas, emitindo uma análise conclusiva. Esse documento deve ser acompanhado de Anotação de Responsabilidade Técnica (ART) ou Registro de Responsabilidade Técnica (RRT) (Grigol, 2020).

\section{Resultados e Discussão}

Reconhecendo a importância das corretas e efetivas ações de proteção e defesa civil, executadas pelos técnicos em defesa civil, visando evitar desastres, apresentam-se 2 (dois) estudos de casos vivenciados por este autor e as propostas de modelos de documentação específica, para servirem de instrumento para atuação desses profissionais ao se depararem com situações de risco de desastres em edificações e áreas de risco. 


\subsection{Estudo de caso 1}

Após ser acionada por um morador, a Coordenadoria Municipal de Proteção e Defesa Civil do Município de PalmasTO (COMPDEC) deslocou-se para atendimento da ocorrência na região sul da capital do Tocantins. Ao chegar ao local, encontrou um cenário no qual encontrava-se uma residência unifamiliar (Figura 1), situada em um nível de aproximadamente 5 (cinco) metros abaixo do nível do terreno vizinho. A residência encontrava-se afastada 12 (doze) metros da divisa do terreno. Já no terreno elevado, funcionava uma igreja que atendia uma grande quantidade de moradores da comunidade.

Figura 1 - Residência localizada em nível abaixo do terreno vizinho.

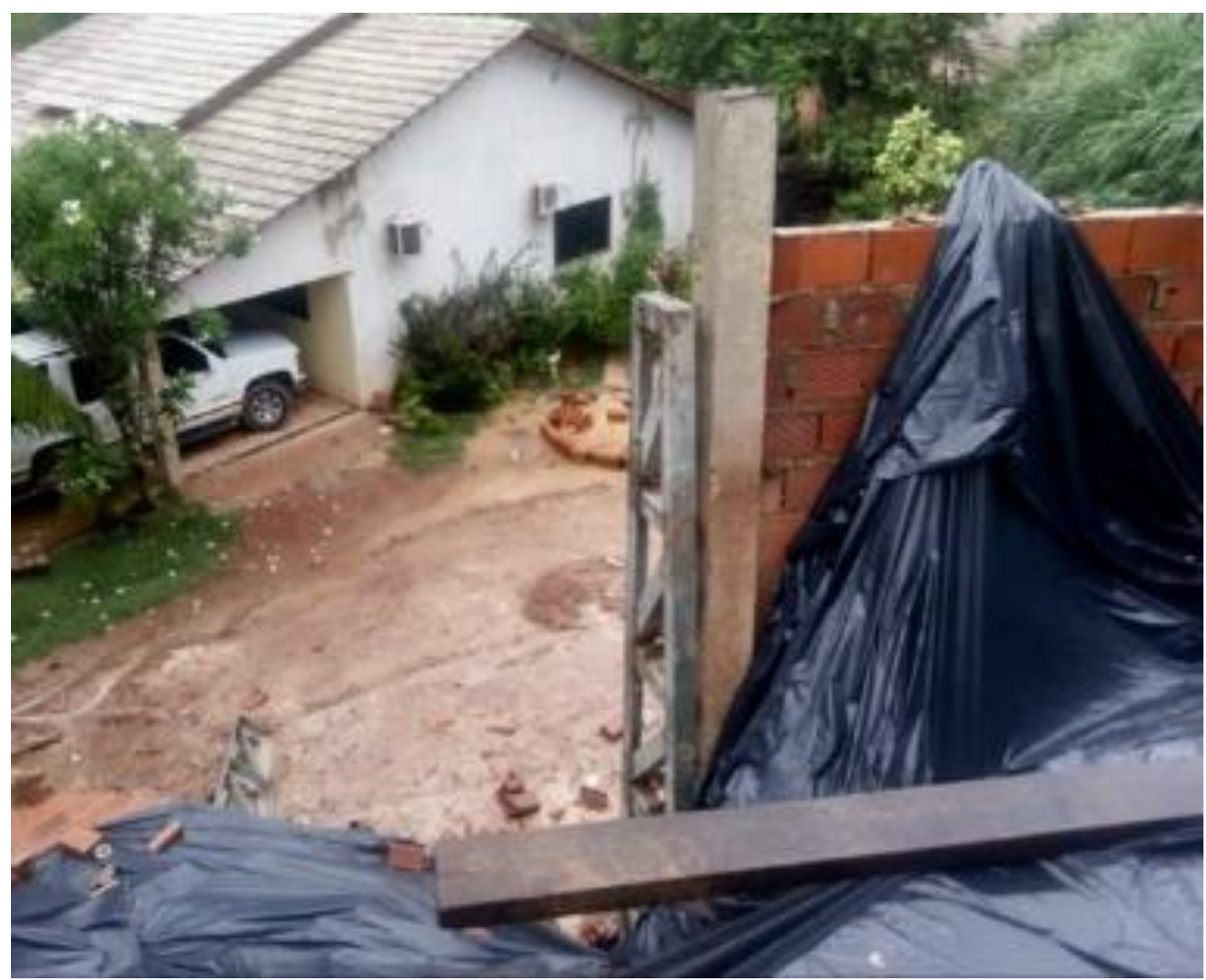

Fonte: COMPEDEC (2019)

Foi observado pela COMPDEC que na divisa entre os dois terrenos havia sido construído um muro de contenção (Figura 2), com o objetivo de estabilizar e conter o talude de terra resultante do corte do aterro, porém, conforme informações do denunciante, essa construção não possuía responsável técnico devidamente habilitado e nem havia sido construída com métodos construtivos adequados. Informou também que o muro não apresentava segurança e poderia haver risco de desmoronamento, colocando em risco sua residência e as pessoas que por ali passavam. Ao verificar todo o cenário, a COMPDEC solicitou apoio técnico à Coordenadoria Estadual de Proteção e Defesa Civil do Estado do Tocantins (CEPDEC), para tomar as devidas providências visando evitar um desastre eminente. 
Figura 2 - Muro de contenção da divisa do terreno.

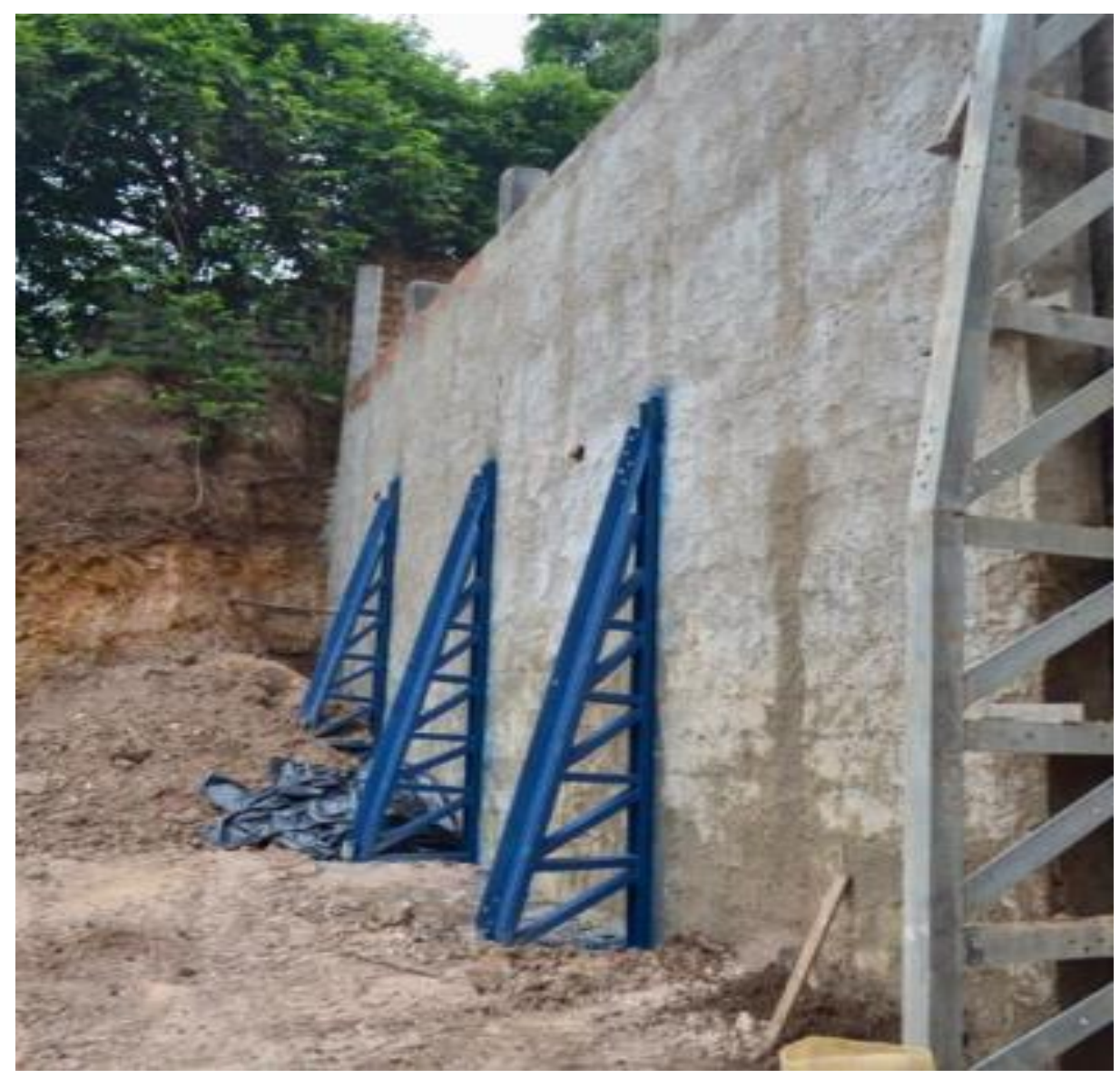

Fonte: COMPEDEC (2019).

A CEPDEC deslocou-se para a ocorrência, e, juntamente com a COMPDEC, analisou todos os cenários e tomou as providências necessárias. Foi constatado que, apesar de existirem treliças apoiando o muro de contenção, essa estrutura foi executada com blocos de vedação e não com blocos estruturais (próprios para esse tipo de estrutura). Observou-se também a presença de rachaduras de caráter ativo, além de manchas de umidade por toda a extensão do muro.

Como havia a construção de um muro de divisa no terreno elevado, próximo ao muro de contenção, e a edificação da igreja encontrava-se a 4 (quatro) metros desse muro, foi lavrado auto de interdição para toda edificação existente no terreno elevado da igreja, por ser considerada uma área com risco eminente por comprometimento estrutural, colocando em risco a segurança das pessoas e do patrimônio existente no local, visto que caso o muro de arrimo tombasse, o deslocamento do solo poderia afetar as fundações das estruturas existentes nas proximidades, o que culminaria no risco de colapso estrutural da igreja. Passou-se fita zebrada na edificação e colocaram-se avisos de que a edificação se encontrava interditada pela COMPDEC. Vale ressaltar que houve pressão dos responsáveis pela igreja, moradores e políticos para que não fosse lavrado o auto de interdição, alegando prejuízos financeiros e à pregação dos cultos religiosos, porém essa argumentação não foi aprovada pelos técnicos da Defesa Civil.

Foi lavrado também auto de interdição da faixa de risco pertencente ao terreno abaixo; visto que, caso o muro de contenção tombasse, teria o risco de atingir pessoas que passassem por ali. Passou-se fita zebrada para demarcar essa área de risco e foi solicitada ao responsável pela construção do muro de contenção a elaboração de projeto e execução de muro, conforme normas técnicas, acompanhado por profissional devidamente habilitado com ART. Caso optasse por não construir um novo muro, conforme as NBRs, o responsável deveria apresentar laudo técnico atestando as condições de segurança do muro com ART. 
Foi constatado que, 2 (dois) dias após a interdição da edificação, ocorreu uma grande chuva que provocou o desmoronamento do muro de arrimo (Figura 3), vindo a colapso parte do muro de divisa de terreno do terreno elevado, afetando também a estrutura da edificação da igreja. Somente foi lavrado auto de desinterdição após a apresentação de toda documentação exigida no auto de interdição, retirada do entulho e execução do novo muro de arrimo, conforme boas técnicas construtivas, NBRs e acompanhamento por profissional devidamente habilitado.

Figura 3 - Muro de contenção colapsado.

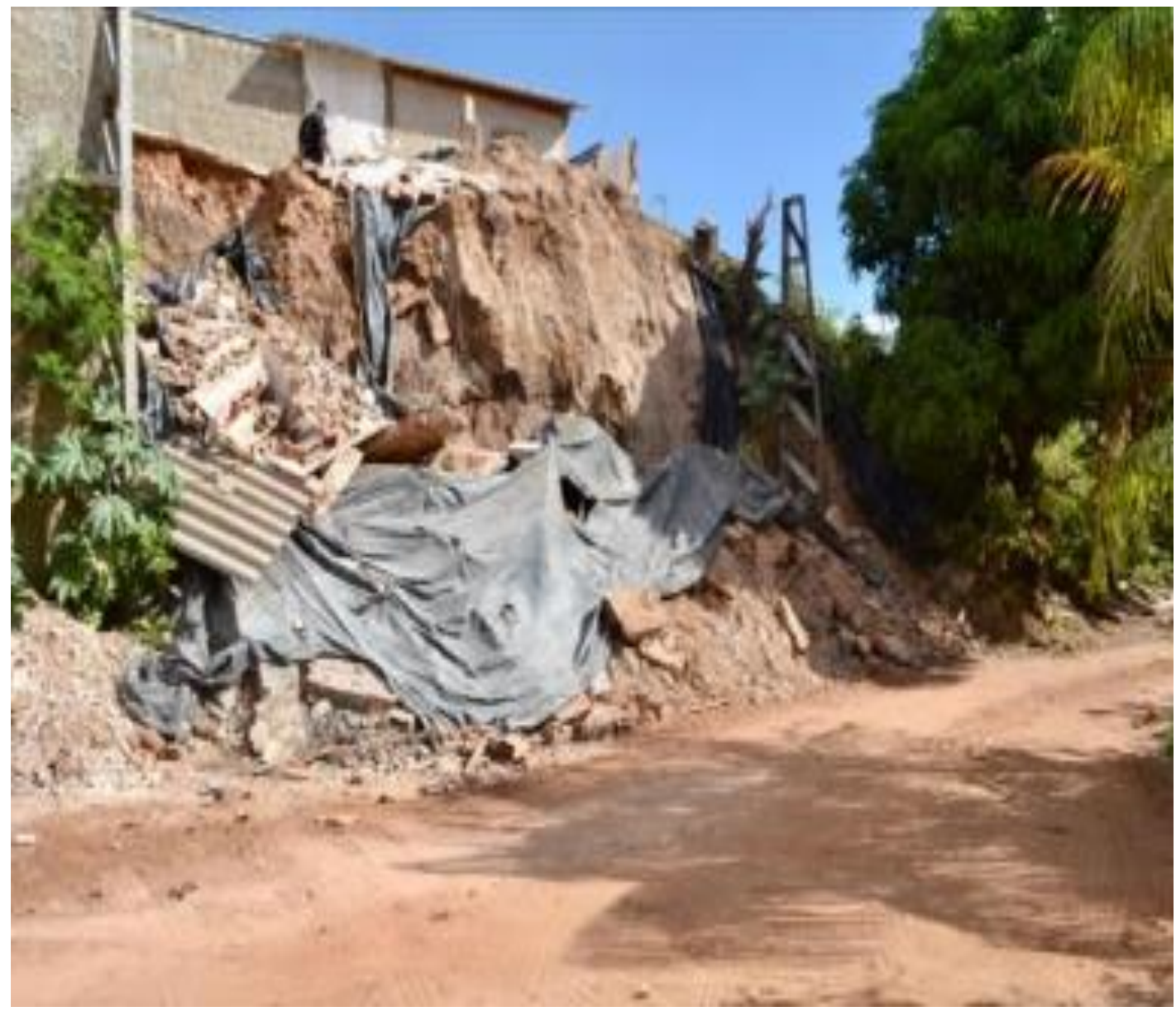

Fonte: COMPEDEC (2019).

\subsection{Estudo de Caso 2}

Foi solicitada pela Secretária da Infraestrutura, Cidades e Habitação do Estado do Tocantins (SEINF), Sra Juliana Passarin, vistoria técnica na ponte do Rio Urubu, na TO-181, localizada no município de Lagoa da Confusão - TO, para avaliar as condições físicas, estruturais e de segurança dessa obra, pois de acordo com a secretaria poderia haver risco de desabamento causado pelos problemas estruturais existentes na estrutura da ponte (Figura 4). 
Figura 4 - Ponte danificada sobre o Rio Urubu.

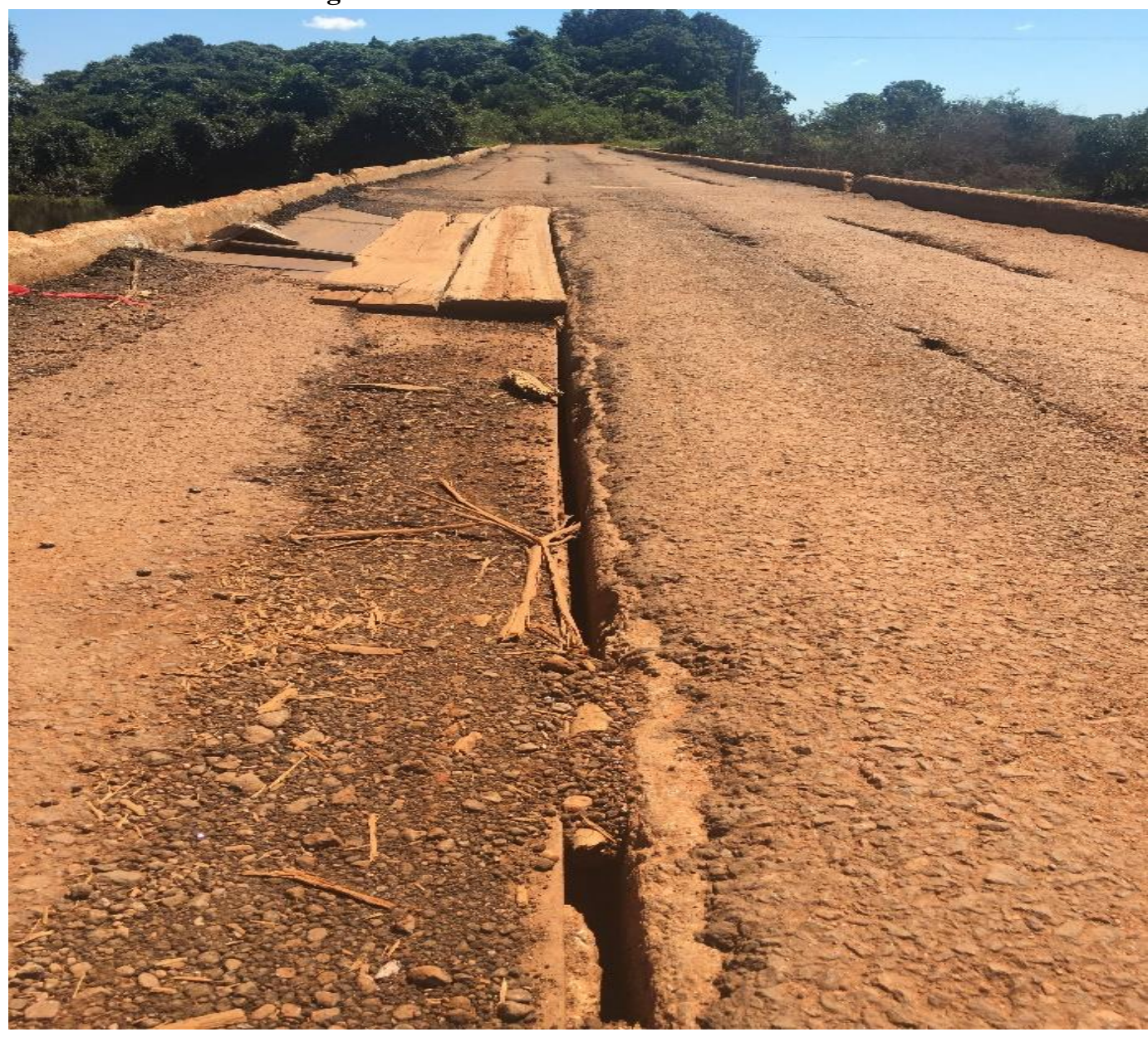

Fonte: Autor (2019).

A CEDEC se deslocou até o local, acompanhada por engenheiros civis da Agência Tocantinense de Transportes e Obras (AGETO); e, ao chegarem ao local, constatou-se um cenário em que parte dos tabuleiros de concreto armado da ponte encontravam-se danificados, com presença de armaduras corroídas e expostas, além de concreto em alto grau de degradação (Figura 5); e, em alguns pontos, havia apenas aço sem a cobertura física do concreto, que é responsável por proteger as armaduras de agentes químicos corrosivos. Havia também a presença de chapas metálicas e tábuas de madeira (Figura 6), que estavam sendo utilizadas de improviso para substituir os tabuleiros de concreto armado, servindo de estrutura para passagem dos veículos. 
Research, Society and Development, v. 11, n. 1, e45111125066, 2022

(CC BY 4.0) | ISSN 2525-3409 | DOI: http://dx.doi.org/10.33448/rsd-v11i1.25066

Figura 5 - Tabuleiros danificados e armaduras expostas.

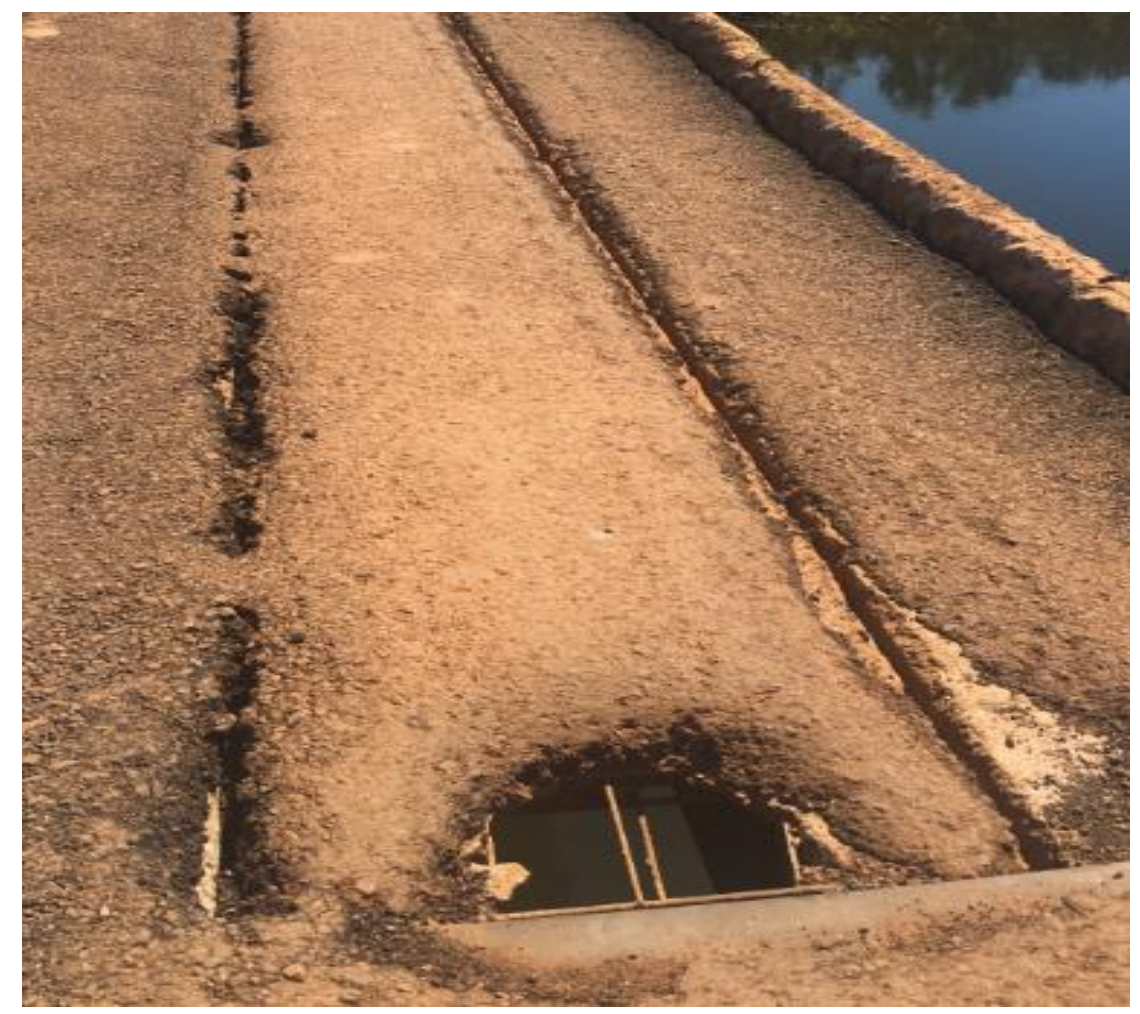

Fonte: Autor (2019).

Figura 6 - Improvisos na substituição dos tabuleiros danificados.

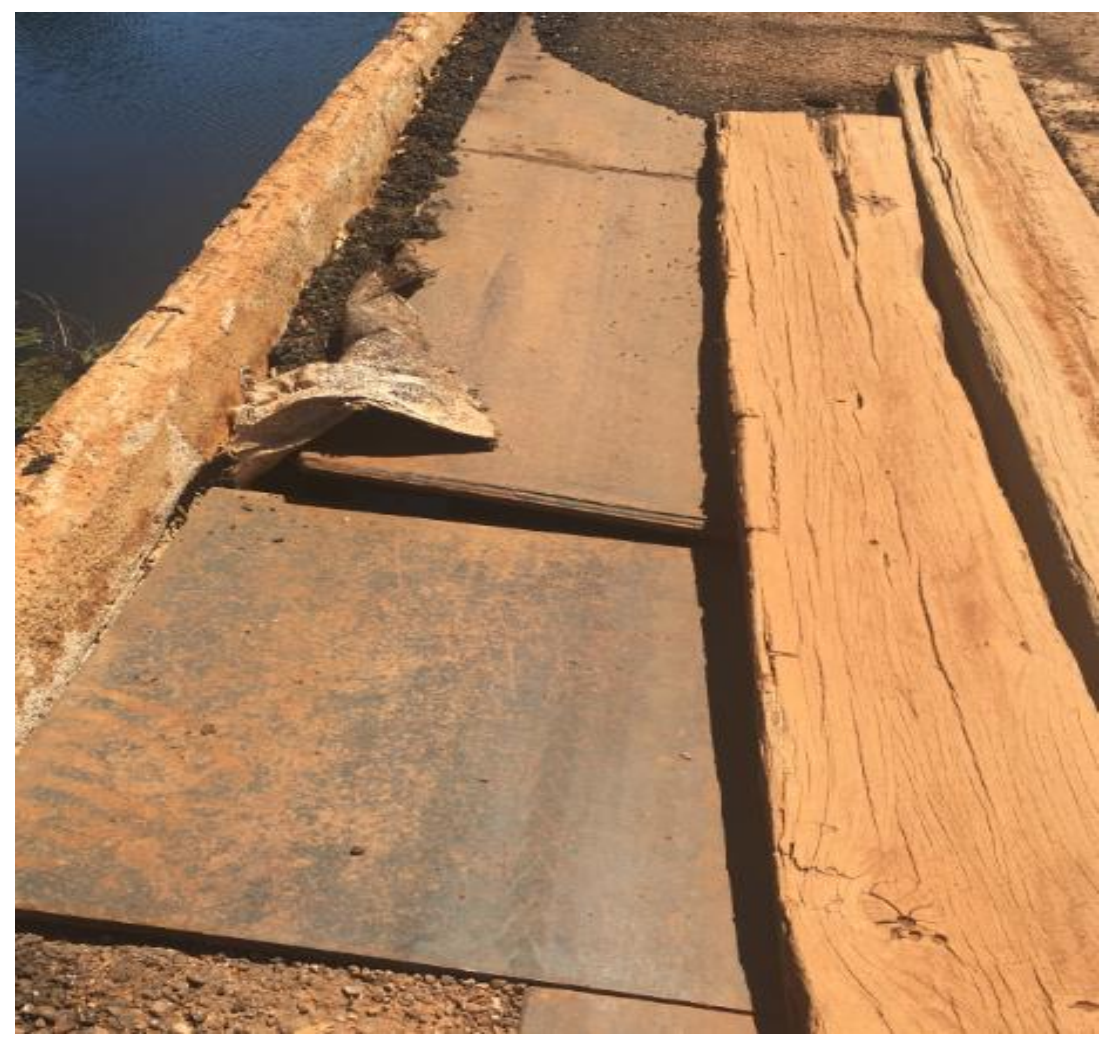

Fonte: Autor (2019). 
Após vistoriar a estrutura inferior da ponte, notou-se a existência de vigas de concreto armado em processo de rompimento, com armaduras expostas, concreto deteriorado e deslocamentos excessivos desses elementos estruturais (Figura 7).

Figura 7 - Vigas deslocadas e armaduras expostas.

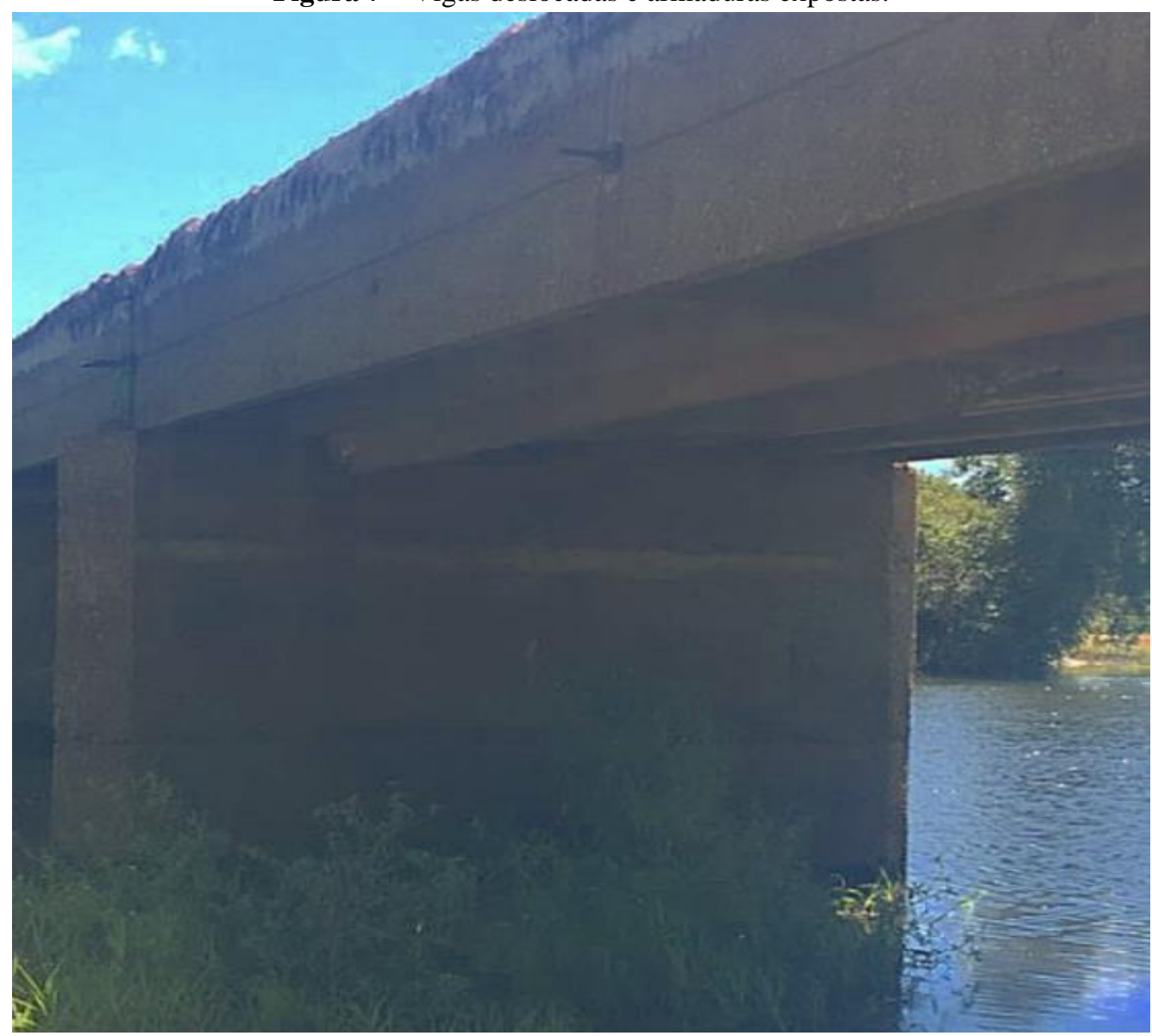

Fonte: Autor (2019).

Foi constatada também a deterioração avançada das paredes de concreto de sustentação da ponte, próximas às cabeceiras, visto que o concreto se apresentava com segregação e agregados graúdos expostos; o que, com o passar do tempo, poderia provocar perda do cobrimento e corrosão das armaduras. As juntas de dilatação da ponte em análise encontravam-se danificadas, não exercendo seu devido papel de absorver as movimentações que a ponte deve absorver; o que acelera ainda mais a deterioração da obra de arte. Os meios-fios encontravam-se danificados, com ferragem exposta. Foi observado in loco excesso de movimentação acentuada da estrutura da ponte após passagem de veículos pesados e carros de passeio.

Foi constatado pela CEDEC que a ponte se encontrava em estado avançado de deterioração, apresentando problemas estruturais e com risco elevado de colapso estrutural e foi emitido auto de interdição, solicitando reparo imediato com acompanhamento de profissional devidamente habilitado, para sanar as manifestações patológicas citadas. A CEDEC solicitou apoio à AGETO para realizar o bloqueio da ponte, impedindo qualquer tráfego de veículos até a emissão do auto de desinterdição pela CEDEC. No município onde a ponte se encontrava, não existia a COMPDEC, cabendo à CEDEC tomar as providências necessárias para garantir a segurança da população. 


\subsection{Propostas de modelos de documentação}

Visando dar suporte às ações de proteção e defesa civil, foram elaborados por este autor (Figura 8 e 9), modelos de documentos específicos com informações baseadas em modelos utilizados pelo Corpo de Bombeiros Militar do Estado do Tocantins e modelos utilizados pela Defesa Civil Municipal de Maricá-RJ.

Figura 8 - Auto de notificação.

\section{AUTO DE NOTIFICAÇÃO}

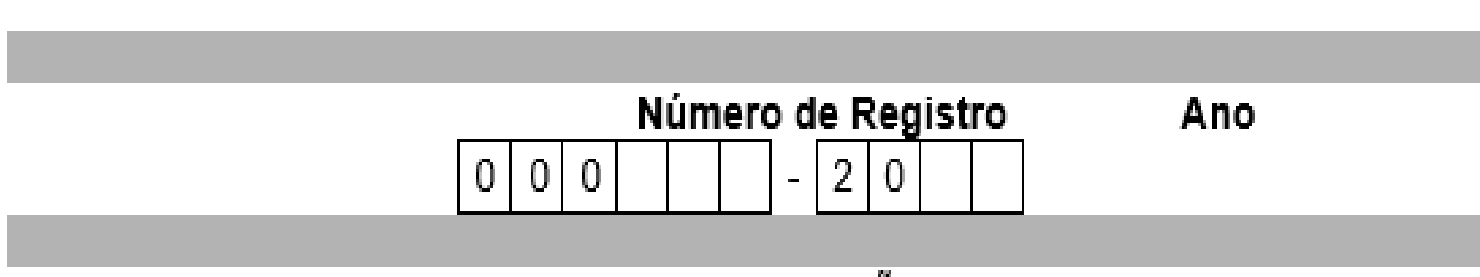

A COORDENADORIA ESTADUAL DE PROTEÇÃO E DEFESA CIVIL, no uso das atribuições que Ihe são conferidas pelo Art. $7^{\circ}$, incisos IV e VIII , da LEI No $12.608 \mathrm{DE}$ 10 DE ABRIL DE 2012, Resolve: - NOTIFICAR o proprietário e/ou responsável pelo(a): ( )Edificação,( ) Estabelecimento, ( ) Residência, ( ) Lote ou Terreno, situado

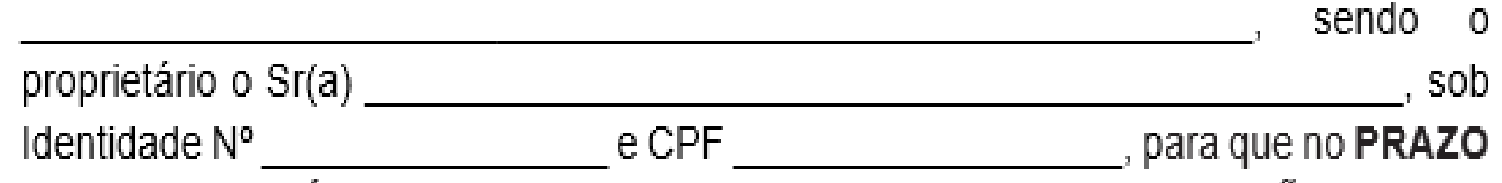
DE___ DIAS ÚTEIS, a contar do recebimento da presente NOTIFICAÇÃO, cumpra, para fins de regularização, a(s) seguinte(s) exigência:

\begin{tabular}{|c|c|}
\hline PROVIDÉNCIAS EXIGIDAS & $\begin{array}{c}\text { Situação } \\
\text { (OK/Não) }\end{array}$ \\
\hline & \\
\hline
\end{tabular}

Nestes termos,

O notificado encontra-se ciente da medida.

Notificado:

CEDEC:

CPF:

$1^{\mathrm{a}}$ Via - Notificado

$2^{\mathrm{a}} \mathrm{Via}$ - CEDEC

Fonte: Autor (2019). 
Figura 9 - Auto de interdição.

\section{AUTO DE INTERDIÇÃO}

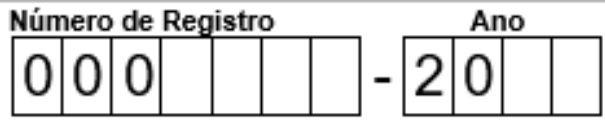

INTEGRAL

PARCIAL

A COORDENADORIA ESTADUAL DE PROTEÇÃo E DEFESA CIVIL, no uso das atribuições que lhe são conferidas pelo Art. 70, incisos IV e VIII, da LEI No 12.608, DE 10 DE ABRIL DE 2012, Resolve: Notificar o proprietário e/ou responsável, referente à INTERDIÇÃo do (a): ( ) Edificação, ( ) Estabelecimento, ( ) Residência, ( ) Lote ou Terreno, situado sendo o(a) proprietário(a) ou possuidor(a) o(a) Sr. (a)

sob Identidade № e CPF

o imóvel possui habitantes. No entanto consta-se a razão da(s) irregularidade(s) identificada(s) por ocasiẫo da vistoria técnica realizada às horas do dia

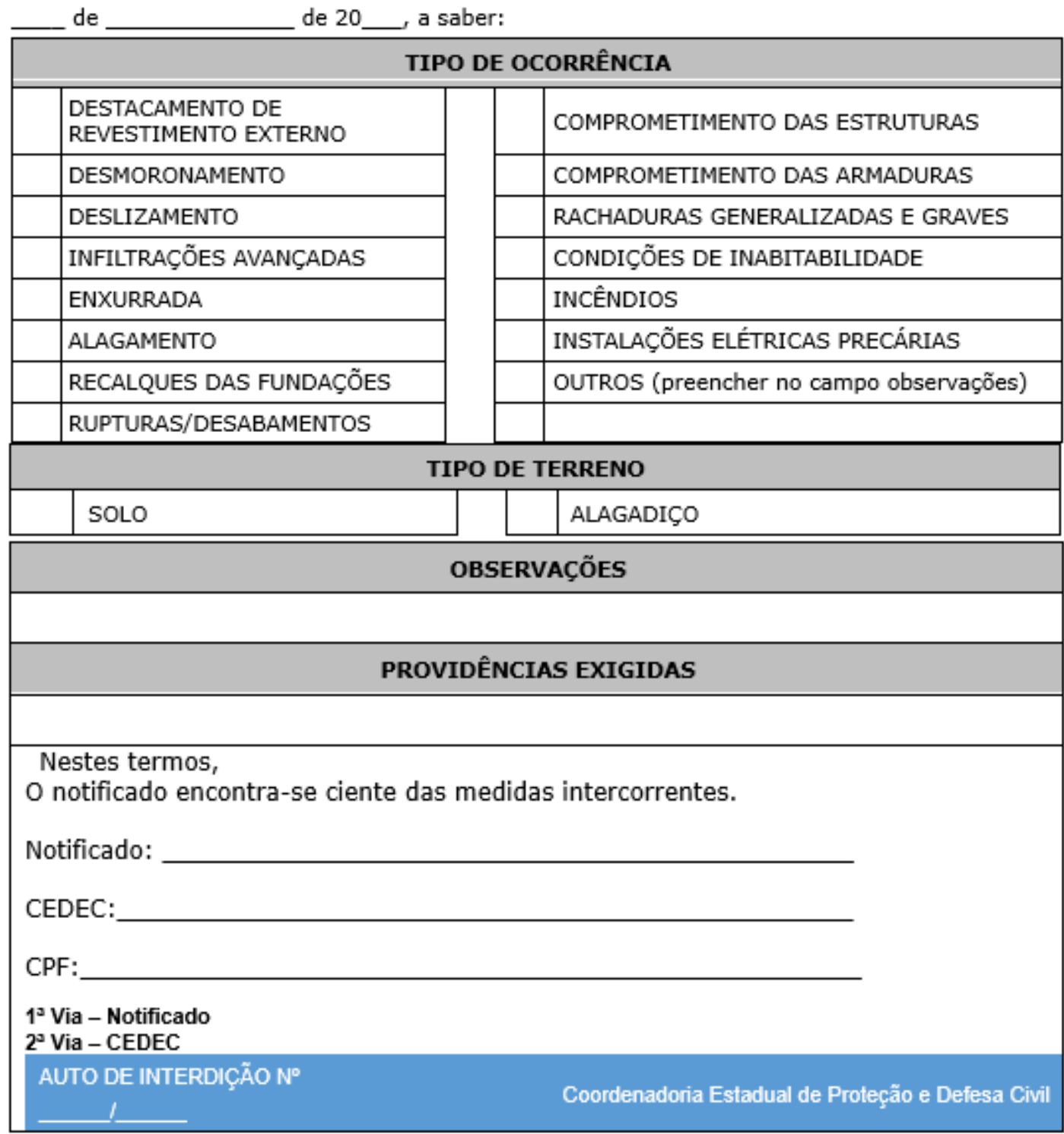

Fonte: Autor (2019). 
Os autos foram montados com informações que o autor julga necessárias para atuação do técnico em defesa civil. Dentre as propostas de documentação tem-se: auto de notificação e auto de interdição, que são os documentos mais utilizados no dia a dia pelos técnicos das CEDECs e COMPEDECs.

\section{Conclusão}

Cabe às COMPDECs, com o apoio das CEPDECs, caso seja necessário, tomar efetivas ações de proteção e defesa civil, visando minimizar os desastres em edificações e áreas de risco. É de extrema importância que os técnicos de defesa civil estejam preparados para tomarem decisões nas mais diversas situações de risco, devendo avaliar todos os cenários possíveis em curto espaço de tempo, muitas vezes sem equipamentos adequados e com pouca visibilidade, pois muitas ocorrências acontecem no período noturno ou com o tempo chuvoso. Quando a CEDEC ou a COMPDEC é acionada, muitas vezes a situação pode estar em elevado risco, devendo o técnico em defesa civil avaliar todas as condições de segurança estruturais antes de adentrar qualquer local, pois ele pode estar correndo risco de vida.

Manifestações patológicas, ruídos, estalos devem ser considerados, pois trata-se de avisos de que algo não está correto, devendo ser dada a devida atenção. Vale ressaltar que, quando houver dúvidas de como atuar, o técnico em defesa civil deve solicitar apoio de profissionais especializados no assunto pertinente; e, caso verifique que há qualquer sinal de risco de colapso, deve ser elaborado imediatamente auto de interdição, devendo cumprir as exigências legais até que sejam sanadas todas as irregularidades.

Quando o objeto em risco for uma obra ou um serviço, deve ser aplicado o auto de embargo e não o auto de interdição, pois nem sempre é necessária à sua aplicação; quando a situação não apresentar riscos estruturais à segurança das edificações ou áreas, pode ser aplicado o auto de notificação, no qual é dado um prazo para o autuado cumprir as pendências relacionas nesse documento. O Parecer Técnico deve ser elaborado por profissional devidamente habilitado, quando solicitado por autoridade competente. Já o Laudo Técnico deve ser solicitado caso o técnico em defesa civil precise de um documento técnico fundamentado cientificamente, elaborado por profissional especialista em ART relacionada a um assunto que exija responsabilidade técnica para garantir a segurança do local.

Como citado no Estudo de Caso 1, sempre vão haver pressões externas, sejam de políticos, moradores, empresários e imprensa, porém o técnico deve tomar a decisão correta, e se resguardar, pois quando o desastre acontece, todas essas pressões são sanadas, e o agente público pode responder judicialmente pelos atos de omissão de seus deveres. A Coordenadoria Estadual de Proteção e Defesa Civil tem papel fundamental na minimização de desastres em edificações e em áreas de risco, devendo dar o apoio necessário às COMPDECs, para a realização das ações. E, em cidades que não existem as COMPDECs, ela deve atuar ostensivamente para resguardar e garantir a segurança da população contra desastres.

A Defesa Civil é mais que uma organização, é um órgão responsável por salvar vidas, "a Defesa Civil somos todos nós!".

\section{Referências}

Aleixo, H. S. P., Eloy, G. R. \& da Silva Junior, L. A. (2019). Problemas patológicos-Estudo de caso na Escola Estadual Antônio Papini em João Monlevade/MG. Research, Society and Development, 8(6), e38861062.

Barros, J. P. B. (2019). Levantamento das patologias presentes em fachadas de edifícios históricos na cidade de Pombal/PB: o caso da Escola Estadual de Ensino Fundamental João da Mata. p. 63. Trabalho de Conclusão de Curso (Bacharel em Engenharia Civil) - Universidade Federal de Campina Grande, Pombal/PB. http://dspace.sti.ufcg.edu.br:8080/jspui/bitstream/riufcg/10326/1/JO\%C3\%83O\%20PAULO\%20BATISTA\%20 BARROS\%20-\%20TCC\%20\%20ENGENHARIA\%20CIVIL\%202019.pdf. Acesso em: 12 fevereiro de 2020.

Brasil. (2007). Lei $n^{\circ} 1.787$, de 15 de maio de 2007. Dispõe sobre a Segurança contra Incêndio e Pânico em edificações e áreas de risco no Estado do Tocantins. Publicado no Diário Oficial n 2.407. Palmas. www.to.gov.br/bombeiros/leis-estaduais/5scoko7cf3s 4 
Brasil. (2012). Lei $n^{\circ}$ 12.608, de 10 de abril de 2012: Institui a Política Nacional de Proteção e Defesa Civil - PNPDEC; dispõe sobre o Sistema Nacional de Proteção e Defesa Civil - SINPDEC e o Conselho Nacional de Proteção e Defesa Civil - CONPDEC; autoriza a criação de sistema de informações e monitoramento de desastres; altera as Leis $\mathrm{n}^{\circ} \mathrm{s} 12.340$, de $1^{\circ}$ de dezembro de 2010, 10.257, de 10 de julho de 2001, 6.766, de 19 de dezembro de $1979,8.239$, de 4 de outubro de 1991, e 9.394, de 20 de dezembro de 1996; e dá outras providências. Brasília, 2012. www.planalto.gov.br/ccivil_03/_ato20112014/2012/lei/112608.htm

Carneiro, J. S., Araújo, R. S., Guimarães, M. S., Souza, T. R. S. \& de Souza, T. H. S. (2019). Identificação das manifestações patológicas do palácio episcopal de Caxias/MA/Identification of the pathological manifestations of the episcopal palace in the city of Caxias/MA. Brazilian Journal of Development, 5(4), 2789-2798.

Freitas, C. \& Nunes, B. (2012). Como e por que um prédio desaba. Revista Veja, https://veja.abril.com.br/brasil/como-e-por-que-um-predio-desaba/>

Gomes, B. M. M., Santos Faro, A. A. \& Nascimento, T. M. (2017). Inspeção da Qualidade de Habitações Populares Após Entrega. Revista de Engenharia e Pesquisa Aplicada, 2(3).

Grigol, R. B. (2020). Laudo Técnico de Engenharia Civil. Carluc Engenharia e Consultoria. www.carluc.com.br/documentos/laudo-tecnico-de-engenhariacivil/

Guerra, F. L. \& Peres, R. M. (2011). Biodeterioração em edificação histórica: estudo do ataque de fungos filamentosos. Programa de pós-graduação em Arquitetura e Urbanismo da Universidade Federal de Pelotas. Pelotas. https://www2.ufpel.edu.br/enpos/2011/anais/pdf/SA/SA_00442.pdf

Helene, P. \& Figueiredo, E. P. (2003). Manual de reparo, proteção e reforço de estruturas de concreto. Red Rehabilitar, Cap. Introdução, p. $19-34$.

Iantas, L.C. (2010). Estudo de caso: análise de patologias estruturais em edificação de gestão pública. 57f. Monografia (Especialização em Construção de Obras Públicas) - Universidade Federal do Paraná. Curitiba.

Medeiros, M. H. F. (2008). Corrosão do concreto é causada por umidade e gases nocivos. AECweb, Revista Digital, Brasília. http://www. aecweb. com. $\mathrm{br} / \mathrm{cont} / \mathrm{m} / \mathrm{rev} /$ corrosao-do-concreto-e-causada-por-umidade-egases-nocivos_6412_0_1>

Milititsky, J., Consoli, N. C. \& Schnaid, F. (2015). Patologia das Fundações, oficina de textos, 191.

Ribeiro, A. C. R. G., Azevedo, F. G., Ferreira, F. G. D. \& Azevedo Filho, R. D. (2019). Impermeabilização a base de polímero acrílico: estudo de caso no tratamento de infiltração da laje de cobertura. Revista Eletrônica da Estácio Recife, 5(2).

Silva, A. F. P., Barros, H. E. B., Ferreira, D. S., do Nascimento, L. G., Lima, F. É. G. \& Oliveira Bezerra, L. (2021). Patologias em estruturas de concreto armado: estudo de caso. Brazilian Journal of Development, 7(1), 363-374.

Silva, R. A. F. (2012). Aplicação da engenharia natural na estabilização de taludes. 127 f. Dissertação (Mestrado em Engenharia Civil) - Centro de Ciências Exatas e da Engenharia (CCEE) da Universidade da Madeira, Funchal, Portugal. http://repositorio.uma.pt/bitstream/10400.13/535/1/MestradoRubenSilva.pdf

Souza, F. C., Pascoal, I. R. \& Boasquives, V. B. Impermeabilização de lajes com uso de manta asfáltica - Estudo de caso no tratamento de infiltração em laje de cobertura. Trabalho de conclusão de curso (Graduação em Engenharia Civil). Universidade Vale do Rio Doce, 2011.

Souza, G. F. (1997). Eflorescências nas argamassas de revestimento. In: Simpósio Brasileiro de Tecnologia das Argamassas, II, Salvador. Anais... Salvador: CETA / ANTAC.

Torga, M. (2020). Responsável técnico: por que ter um profissional na obra é tão importânte? Engenharia360. https://engenharia360.com/responsaveltecnico-profissional-habilitado-obra-importancia/

Vitório, A. (2003). Fundamentos da patologia das estruturas nas perícias de engenharia. Recife: Instituto Pernambucano de Avaliações e Perícia de Engenharia. 